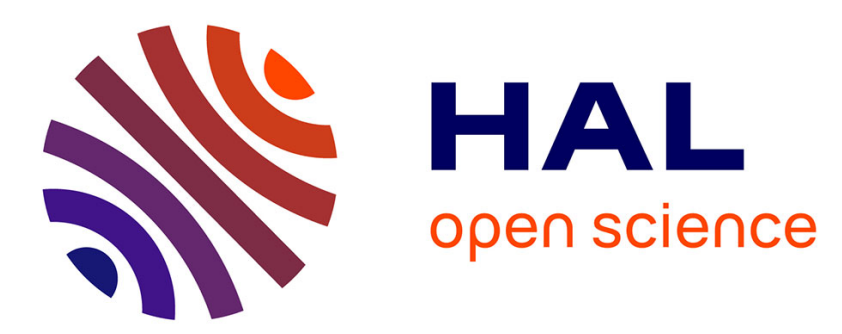

\title{
Through-Space Electrostatic Interactions Surpass Classical Through-Bond Electronic Effects in Enhancing CO 2 Reduction Performance of Iron Porphyrins
}

\author{
Asma Khadhraoui, Philipp Gotico, Winfried Leibl, Zakaria Halime, Ally
}

Aukauloo

\section{To cite this version:}

Asma Khadhraoui, Philipp Gotico, Winfried Leibl, Zakaria Halime, Ally Aukauloo. ThroughSpace Electrostatic Interactions Surpass Classical Through-Bond Electronic Effects in Enhancing CO 2 Reduction Performance of Iron Porphyrins. ChemSusChem, 2021, 14 (5), pp.1308-1315. 10.1002/cssc.202002718. hal-03279600

\section{HAL Id: hal-03279600 https://hal.science/hal-03279600}

Submitted on 6 Jul 2021

HAL is a multi-disciplinary open access archive for the deposit and dissemination of scientific research documents, whether they are published or not. The documents may come from teaching and research institutions in France or abroad, or from public or private research centers.
L'archive ouverte pluridisciplinaire HAL, est destinée au dépôt et à la diffusion de documents scientifiques de niveau recherche, publiés ou non, émanant des établissements d'enseignement et de recherche français ou étrangers, des laboratoires publics ou privés. 


\section{ARTICLE}

\section{Through-Space Electrostatic Interactions Promoting $\mathrm{CO}_{2}$ Reduction Performance of Iron Porphyrins}

Received 00th January 20xx, Accepted 00th January 20xx DOI: $10.1039 / x 0 x \times 00000 x$

\author{
Asma Khadhraoui, ${ }^{a}$ Philipp Gotico, ${ }^{a}$ Winfried Leibl, ${ }^{b}$ Zakaria Halime, ${ }^{* a}$ and Ally Aukauloo* $*^{a, b}$
}

\section{Introduction}

A temporary solution to deal with the mitigation of carbon dioxide $\left(\mathrm{CO}_{2}\right)$ levels in our atmosphere resides in the grand scale capture of $\mathrm{CO}_{2}$ to be buried into rocks. ${ }^{1}$ Although several incentives on this strategy have been launched worldwide, many concerns still persist on the long run stability and cost efficiency of such programs. Such solutions are being considered primarily because of the lack of knowledge on how to massively transform $\mathrm{CO}_{2}$ to energy-rich forms of carbon. We are currently witnessing a substantial effort from chemists to address the issue of capturing and converting $\mathrm{CO}_{2}$ into a fuel or stitching it in a reduced form as a $\mathrm{C} 1$ unit in organic synthesis. ${ }^{2-}$

${ }^{8}$ This promising research field is a priority for our society with the target to set a virtuous cycle through valorization of exhausted $\mathrm{CO}_{2}$. This task is not trivial as activating and adding controlled number of electrons and protons on the stubbornly stable $\mathrm{CO}_{2}$ molecule are exceedingly challenging. ${ }^{9}$ Because of the highly endergonic processes involved in the reduction of $\mathrm{CO}_{2}$, catalysts are required to accelerate these reactions. In molecular chemistry, a great effort is dedicated to design new molecular catalysts inspired by active sites of families of enzymes that have been efficiently developed by nature to achieve these chemical transformations.

Many metal complexes with different sets of ligands have already shown interesting activities. ${ }^{10-15}$ These include metal ions spanning through the first, second, and third row of the periodic table enveloped with designed nitrogenated ligand sets together with sulphur and phosphorus coordinating atoms. Among these, metalloporphyrins have captured a particular attention for the $\mathrm{CO}_{2}$ reduction inasmuch as the hemic models have long been studied as models for the Cytochrome c Oxidase to perform the four-electron reduction of $\mathrm{O}_{2}$ or the reductive activation of $\mathrm{O}_{2}$ by the oxygenases family of enzymes. ${ }^{12,15-22}$ Savéant and coll provided a first thorough electrochemical investigation of the electrocatalytic activity of the iron complex of the parent derivative of the tetra-arylporphyrins, the iron (III) tetra-phenylporphyrin, FeTPP. ${ }^{17,23}$ The synthetic development of functionalized tetraarylporphyrins has led to the sophistication of these molecular catalysts to optimize the electrocatalytic reduction of $\mathrm{CO}_{2}$, with catalytic overpotential and turnover frequency as the main characteristics for performance.

\footnotetext{
Université Paris-Saclay, CNRS, Institut de chimie moléculaire et des matériaux d'Orsay, 91405, Orsay, France. E-mail: ally.aukauloo@universite-paris-saclay.fr, zakaria.halime@universite-paris-saclay.fr

${ }^{b .}$ Université Paris-Saclay, CEA, Institute for Integrative Biology of the Cell (I2BC)

91198, Gif-sur-Yvette, France

+ Electronic Supplementary Information (ESI) available: Synthetic procedures, spectroscopic, and electrochemical experiments. See DOI: 10.1039/x0xx00000x
} 

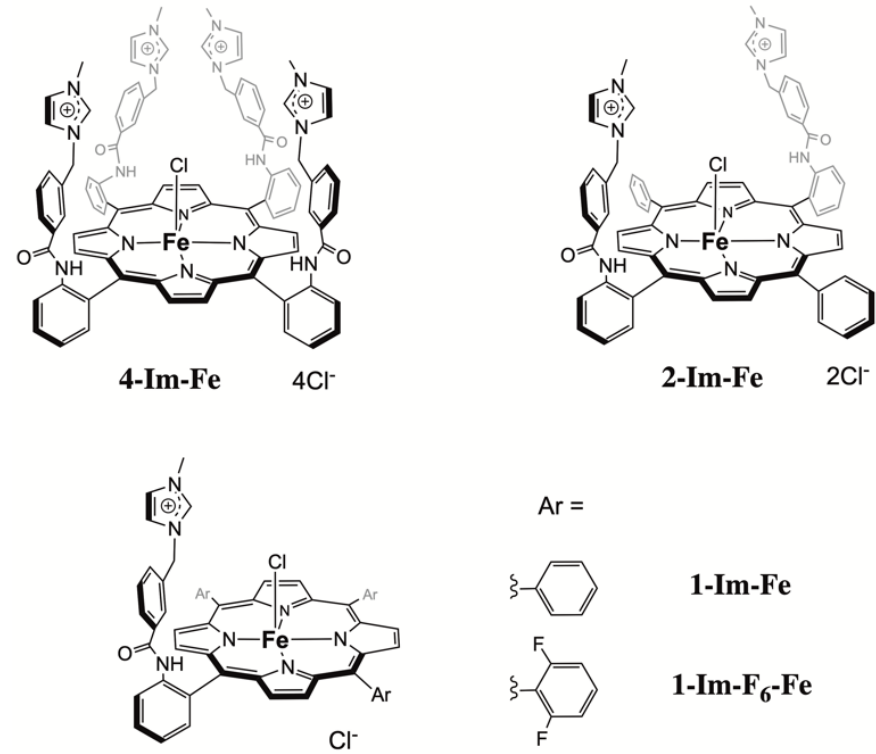

1-Im-Fe

1-Im-F $-\mathrm{Fe}$

Scheme 1 Schematic representation of modified iron-porphyrin catalysts bearing four (4-Im-Fe), two (2-Im-Fe) and one (1-Im-Fe and 1-Im- $\left.\mathrm{F}_{6}-\mathrm{Fe}\right)$ imidazolium arm.

In effect, the porphyrin platform has been put under electronic effects with electron-withdrawing functions to lower the overpotential of the $\mathrm{CO}_{2}$ reduction. ${ }^{18,24}$ However, studies along this path have shown that the beneficial lowering of the overpotential was counterbalanced by lower reaction rate constants and turnover frequencies. ${ }^{25,}{ }^{26}$ The astute move to bring proton donor functions such as phenols by the group of Robert, Costentin, and Savéant (RCS) in the second coordination sphere where catalysis was taking place has led to a gain of orders of magnitude in the catalytic rate constant. ${ }^{27,} 28$ Such an effect was assigned to the rapid delivery of protons to the activation of $\mathrm{CO}_{2}$ to form $\mathrm{CO}$ and water. The same group further introduced cationic ammonium functions on the phenyl groups on the meso positions of the porphyrins with the targeted objective to stabilize the $\mathrm{Fe}^{-}-\mathrm{CO}_{2}^{-}$ intermediate. ${ }^{24}$ The benefit of the presence of these cationic functions was demonstrated by an important lowering of the overpotential together with enhanced electrocatalytic activities. A similar effect in the electrocatalytic activity was reached when imidazolium groups as ionic liquid components were hooked to the aryl groups on the periphery of the porphyrin macrocyle again pertaining the through-space electrostatic stabilizing action and promoting the reactivity of the iron porphyrin catlyst. ${ }^{29}$ It is also to be mentioned that different hydrogen bonding donors have been added on the contour of the porphyrin to help capture $\mathrm{CO}_{2}$ with remarkable effects on both turnover frequencies and overpotentials. ${ }^{30-32}$ The same chemical adjustment is also being practiced for other metal complexes showing marked improvement of electrocatalytic activities. ${ }^{19,22,33}$ Turning our attention to the iron porphyrin complexes, most of these achievements have been realized with catalysts bearing second coordination sphere groups on the ortho position of the porphyrin meso aryl rings in fully substituted systems with a $C_{4}$ symmetry. The ortho position was selected to place these groups above the metallic center where interactions with a $\mathrm{Fe}^{\prime}-\mathrm{CO}_{2}$ intermediate are expected to take place. Of note, the symmetrical introduction of these groups on the four meso aryls of the porphyrin platform is mainly motivated by synthetic practicality.

Using our previously reported catalyst bearing four imidazolium arms in the ortho position of the meso aryl (4-ImFe, Scheme 1) as a reference catalyst, ${ }^{29}$ in this work, our first interrogation concerns the question whether the exaltation of the observed electrocatalytic properties is the collective contribution of all four groups on the porphyrin rim. To address this important question, we have designed two iron porphyrins holding two and one imidazolium motifs hereby abbreviated as 2-Im-Fe and 1-Im-Fe, respectively (Scheme 1). To further examine whether combining effects of different chemical functions may provide new reactivity patterns, we have also been interested in this study to combine the through-structure electronic effects (that normally lead to lowering of overpotential but with a marked drop in the electrocatalytic activity) with an electrostatic one (that through-stabilization of the $\mathrm{Fe}^{-}-\mathrm{CO}_{2}{ }^{-}$intermediate boosts the electrochemical conversion of $\mathrm{CO}_{2}$ ). As such, the monosubstituted imidazolium derivative $\mathbf{1}-\mathbf{I m}$-Fe was compared to its analogue bearing six fluorine atoms as inductive electronwithdrawing groups (abbreviated as $\mathbf{1}-\mathbf{I m}-\mathbf{F}_{\mathbf{6}}-\mathbf{F e}$ ) to investigate the cumulative action of these groups.

We found that the overpotential of 4-Im-Fe, 2-Im-Fe and 1-ImFe catalysts increases with the number of embarked imidazolium units ranging from 230 to 430 to $620 \mathrm{mV}$, respectively, compared to $680 \mathrm{mV}$ for the parent tetra-phenyl iron porphyrin, FeTPP. Importantly, we evidenced a gain of six orders of magnitude for the turnover frequencies going from the tetra- to the mono-substituted catalyst. Accordingly, in line with A. Warshel's electrostatic theory in explaining the unmatched reactivity of enzymes, ${ }^{34-36}$ we found that the electrocatalytic performance trend of through-space electrostatic interaction models outperforms the classical electronic effects strategy. This is further exemplified for the 1Im- $\mathbf{F}_{\mathbf{6}}-\mathbf{F e}$ complex whose turnover frequency is three orders of magnitude higher than the $\mathrm{FeTPPF}_{\mathbf{8}}$ derivative at similar overpotential.

\section{Results and discussion}

\section{Synthesis of modified iron-porphyrins holding imidazolium groups}

Catalysts 2-Im-Fe, 1-Im-Fe and $\mathbf{1}-\mathbf{I m}-\mathbf{F}_{\mathbf{6}}-\mathbf{F e}$ were prepared starting from three different aminophenylporphyrins having two (3) or one (7 and $\mathbf{7}^{\prime}$ ) amine functions (Scheme 2). Porphyrin 3 was obtained by the reduction of the nitro groups of synthon $\mathbf{2}$ that was prepared according to the $2+2$ Lindsey condensation of benzaldehyde and the orthonitrophenyldipyrromethane, ${ }^{37,38}$ which in turn resulted from an acid-catalyzed condensation of pyrrole and orthonitrobenzaldehyde. To keep a similar general topology, only the $\alpha \alpha$ atropisomer, having two amino groups in the same side with respect to the porphyrin plane was included in this study. 

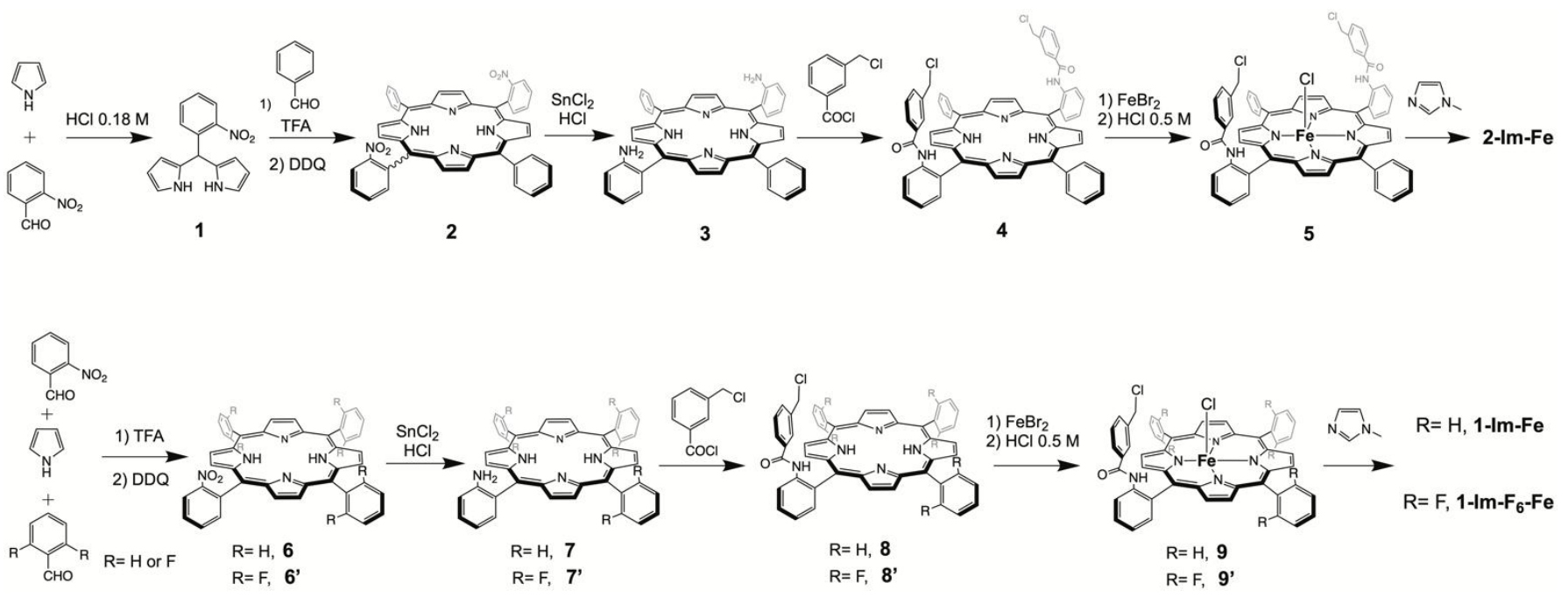

Scheme 2 Synthesis of iron porphyrin catalysts 2-Im-Fe, 1-Im-Fe and 1-Im- $\mathbf{F}_{6}-\mathrm{Fe}$

The condensation of 4 equivalents of pyrrole and 1 equivalent of ortho-nitrobenzaldehyde with 3 equivalents benzaldehyde or di-ortho-fluorobenzaldehyde results in the mono-(orthonitrophenyl)porphyrin 6 and $\mathbf{6}^{\prime}$ respectively, which were subsequently reduced to the amino analogues $\mathbf{7}$ and $\mathbf{7}^{\prime}$ respectively. Starting from these different aminophenylporphyrins, we used a similar synthetic tactic that we previously reported for catalyst $4-I m-F e .{ }^{29}$ In the first step, the benzylic linker is introduced in a reaction between the porphyrin's amine groups and the 3-(chloromethyl)benzoyl chloride. When the amino groups are in the ortho position of the meso aryls of the porphyrin $\left(\mathbf{4}, \mathbf{8}\right.$ and $\left.\mathbf{8}^{\prime}\right)$, the obtained semi-rigid aryl-amide-aryl motif was shown to be optimal for positioning functional groups in pre-organized fashion close to the coordination sphere of the metal ion lying in the center of the porphyrin ring. ${ }^{39-42}$ In the next step of this synthesis, a ferrous chloride salt was used in presence of a base to insert the iron ion in the $\mathrm{N} 4$ coordinating cavity of the porphyrins. The obtained iron complexes 5, 9 and 9' were then treated with stoichiometric amounts of $\mathrm{N}$-methylimidazole to substitute the benzylic chlorides with methyimidazolium groups and yield the targeted catalysts 2-Im-Fe, 1-Im-Fe and 1Im- $\mathbf{F}_{6}-\mathrm{Fe}$ as chloride salts. The above-mentioned porphyrin ligands were characterized by ${ }^{1} \mathrm{H}-,{ }^{13} \mathrm{C}-\mathrm{NMR}, \quad$ UV-Vis spectroscopies, HR-ESI mass spectrometry and the metallated porphyrins were characterized by UV-Vis spectroscopy and HRESI mass spectrometry. Detailed synthetic procedures and characterizations are described in the ESI.

\section{Influence of the number of methylimidazolium groups}

Under argon atmosphere in presence of $0.1 \mathrm{M}$ of tetra- $\mathrm{N}$ butyl-ammonium hexafluorophosphate $\left(\mathrm{TBAPF}_{6}\right.$ ) as supporting electrolyte and DMF as solvent, all the functionalized iron porphyrins in Scheme 1 as well as the parent nonfunctionalized iron tetra-phenylporphyrin (FeTPP) display three reversible waves corresponding to the formal redox couples $\mathrm{Fe}^{I I 1 / 1}, \mathrm{Fe}^{11 / 1}$, and $\mathrm{Fe}^{1 / 0}$ couples (Figure 1 and Table 1).
Recent reports suggest that the second and the third redox waves can be mainly centered on the porphyrin because of the redox non-innocent character of the tetra-pyrrolic ligand and therefore can be alternatively formulated as $\mathrm{Fe}^{\text {"porph/Fe"porph }}{ }^{\cdot-}$ and $\mathrm{Fe}^{\prime \prime}$ porph ${ }^{\bullet-} / \mathrm{Fe}^{\prime \prime}$ porph ${ }^{{ }^{\circ 2}-}$ couples (porph $=$ porphyrin). ${ }^{43,44}$ Catalysts $2-I m-F e$ and 1-Im-Fe were designed in a way to divide the number of methylimidazolium groups in the reference catalyst $4-\mathbf{I m}-\mathbf{F e}$ by two and by four, respectively while maintaining a similar general topology. Compared to this reference catalyst, the first direct impact of decreasing the number of methylimidazolium groups can be observed under argon atmosphere with a 200 and $390 \mathrm{mV}$ cathodic shift of the third reduction wave $\left(\mathrm{Fe}^{1 / 0}\right)$ for catalysts 2Im-Fe and 1-Im-Fe, respectively (Figure $1 \mathrm{a}$ and Table 1 ). This significant potential shift indicates that, similar to the throughstructure inductive effect, the through-space charge stabilization of the catalyst's anionic forms, i.e. $\mathrm{Fe}^{\prime}$ and $\mathrm{Fe}^{\mathrm{O}}$, by the imidazolium arms is also a cumulative effect.

The CVs of all three catalysts in a $\mathrm{CO}_{2}$-saturated solution and in presence of $\mathrm{H}_{2} \mathrm{O}$ as proton source show an important catalytic current on the third reduction wave (Figure 1b). Gas chromatography (GC) analysis of the electrochemical reaction headspace during bulk electrolysis experiments confirmed that for all three catalysts, the observed catalytic current corresponds exclusively to the $2 \mathrm{e}^{-}$reduction of $\mathrm{CO}_{2}$ to $\mathrm{CO}$ with a Faraday efficiency ranging from 89 to 93 \% (Figure S28-31). The catalytic waves of the three catalysts were also analyzed using the Foot-of-the-Wave (FOW) method, introduced by $\mathrm{RCS}^{24,26,45-47}$ to estimate the turnover frequency (TOF) free from secondary phenomena (substrate and co-substrate depletion, product inhibition, catalyst degradation, etc.) which would otherwise require increasing scan rates during $\mathrm{CV}$ measurements to reach the ideal canonical S-shaped catalytic wave. A plot of the kinetic parameter $\log (\mathrm{TOF})$ against the thermodynamic parameter of overpotential, $\eta=\mid E\left(\mathrm{Fe}^{1 / 0}\right)-$ $E^{\circ}\left(\mathrm{CO}_{2} / \mathrm{CO}\right) \mid$, with a reported value of $0.740 \mathrm{~V} v$ s NHE for the latter in $\mathrm{DMF} / \mathrm{H}_{2} \mathrm{O},{ }^{25}$ illustrates important effects of the 
porphyrin substituents on the electrocatalytic behavior (Figure 1c).

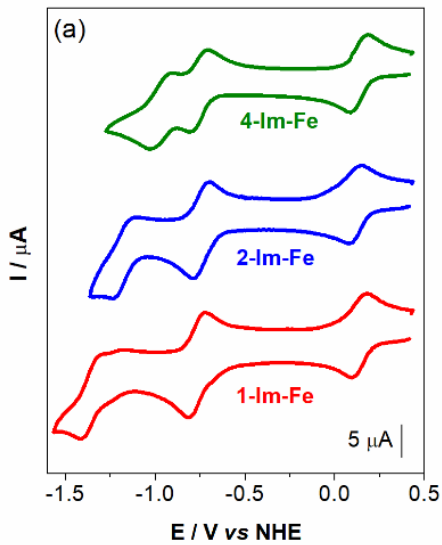

the catalyst) or the catalytic conditions such as acid $\mathrm{p} K_{a}$ and concentration can result in different values of correlation

Figure 1 Cyclic voltammograms of $1 \mathrm{mM}$ of modified iron porphyrin complexes 4-Im-Fe (green), 2-Im-Fe (blue), and 1-Im-Fe (red) in dimethylformamide (DMF) containing 0.1 M TBAPF $_{6}$ at $25^{\circ} \mathrm{C}$ (a) under argon and (b) under 1 atm of $\mathrm{CO}_{2}$ with $5.5 \mathrm{M} \mathrm{H}_{2} \mathrm{O}$. (c) Comparison of the turnover frequency (TOF) calculated from FOW analysis as a function of catalytic

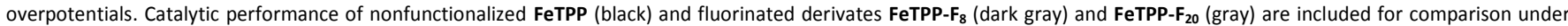
the same experimental conditions in (b).

For example, the classical through-structure strategy of decreasing the overpotential by decorating the porphyrin ring with inductive electron-withdrawing fluorine groups results in linear decrease of the $\log$ (TOF) (comparison within FeTPP, FeTPP- $\mathbf{F}_{8}$, and FeTPP- $\left.\mathbf{F}_{20}\right){ }^{26,}{ }^{29}$ The beneficial lowering of the overpotential because of the thermodynamic ease of reducing the iron porphyrin comes at a detrimental cost of lower catalytic rate constant.

Interestingly, our findings revealed an obvious structure/reactivity trend illustrated by an increase of the TOF and the reaction overpotential with decreasing numbers of cationic methylimidazolium groups when going from 4-Im-Fe to 2-Fe-Im and to 1-Im-Fe. From these findings, a linear correlation like that observed for the through-structure inductive effect can also be drawn for the through-space electrostatic effect but the latter is characterized by significantly higher reaction rates. We previously attributed the catalytic enhancement observed with the imidazoliummodified catalyst 4-Im-Fe, in comparison with FeTPP and its fluorinated derivatives, to the additional role played by the positively charged methylimidazolium groups in stabilizing the negatively charged $\mathrm{Fe}-\mathrm{CO}_{2}^{-}$catalytic intermediate by throughspace electrostatic interactions. ${ }^{29}$ In addition to confirming this through-space effect, this study shows that the amplitude of this effect can be affected by the number of methylimidazolium groups. Importantly, a noticeable difference in the slope of the through-space and throughstructure linear correlations can be clearly observed. The correlation coefficient (inverse slope), extracted from the plot of $\log$ (TOF) vs overpotential (Figure 1c), varies from $118 \mathrm{mV}$ per decade in TOF for the fluorinated derivates to $66 \mathrm{mV}$ per decade in TOF for the imidazolium derivatives. Mayer and coworkers have shown, in the case of $\mathrm{O}_{2}$ reduction by iron porphyrins, that the modification of different parameters involved in the rate-determining step such as the intrinsic catalyst parameter of $E_{\mathrm{Fe}(\mathrm{III} / \mathrm{II})}$ (through ligand modifications of coefficients. $^{48-50}$ However, Costentin and Savéant reported that such correlations only exists within families of catalyst in which the through-structure electronic effects influence in a similar manner the catalyst standard potential on one hand, and the thermodynamics and kinetics of the rate-determining catalytic sequence on the other hand.$^{51}$ Remarkably, we report here for the first time that in this family of imidazoliumfunctionalized iron porphyrins, the overall driving force brought by through-space substituent effects influence also the driving force of the rate-determining sequence in $\mathrm{CO}_{2}$-toCO catalytic reduction which translates in the correlation observed in the $\log$ (TOF) vs overpotential plot (Figure 1c).

To better understand the effect of the number of imidazolium arms on the overall reaction rate, we investigated on a possible change of the nature of the rate-determining step of the electrocatalytic reduction. $\mathrm{CO}_{2}$ binding and proton transfer are in general the two main processes with a significant contribution to the rate-determining step of the reaction because electron transfer processes are considered to be fast at the potential where the electrocatalytic reaction proceeds. The $\mathrm{CO}_{2}$ binding constant of the active form, that is, the formal $\mathrm{Fe}^{0}$ state of the iron porphyrin derivatives, was estimated by recording the $\mathrm{CV}$ responses in $\mathrm{CO}_{2}$-saturated dry DMF and in the absence of a proton source, which prevents any catalytic activity (Figures S9-S12). As shown in Figure 2, there is no direct correlation between the $\mathrm{CO}_{2}$ binding constant and the number of methylimidazolium groups. However, 4-Im-Fe and 2-Im-Fe have a higher $\mathrm{CO}_{2}$ binding constant (14.29 and 18.34 $\mathrm{M}^{-1}$, respectively) compared to $1-\mathrm{Im}-\mathrm{Fe}\left(2.08 \mathrm{M}^{-1}\right)$ containing only one of the methylimidazolium group, but the latter has still a higher value compared to the non-functionalized FeTPP $\left(0.92 \mathrm{M}^{-1}\right)$. The close values of the $\mathrm{CO}_{2}$ binding constant between catalysts with the two and four imidazolium arms suggest that a minimum of two methylimidazolium groups are involved in 'efficient' $\mathrm{CO}_{2}$ capture. The $\mathrm{CO}_{2}$ binding ability of these modified iron porphyrins can be thought of as a 
synergistic effect between the cationic imidazolium groups stabilizing the anionic $\mathrm{CO}_{2}$ adduct and, to lesser extent, the hydrogen-bonding aptitude of the amide groups as such functionalities have been reported to enhance $\mathrm{CO}_{2}$ binding. ${ }^{30}$,

\begin{tabular}{|c|c|c|c|c|c|c|c|}
\hline Catalysts & $E\left(\mathrm{Fe}^{1 / 0}\right) / \mathrm{V}$ & $n^{a} / m V$ & TOF $_{\max }^{\mathrm{b}}$ & Log TOF & Faraday Efficiency $^{c}$ & $\mathrm{~K}_{\mathrm{CO}_{2}}{ }^{\mathrm{d}} / \mathrm{M}^{-1}$ & $\operatorname{KIE}^{\mathrm{e}}\left(\boldsymbol{k}_{\mathrm{cat}, \mathrm{H}_{2} \mathrm{O}} / \boldsymbol{k}_{\mathrm{cat}, \mathrm{D}_{2} \mathrm{O}}\right)$ \\
\hline 4-Im-Fe & -0.969 & 229 & $3.10 \times 10^{2}$ & 2.49 & $91 \%$ & 14.29 & $0.43( \pm 0.08)$ \\
\hline 2-Im-Fe & -1.168 & 428 & $8.57 \times 10^{5}$ & 5.93 & $93 \%$ & 18.34 & $1.12( \pm 0.13)$ \\
\hline 1-Im-Fe & -1.357 & 617 & $2.05 \times 10^{8}$ & 8.31 & $89 \%$ & 2.08 & $1.02( \pm 0.12)$ \\
\hline $1-\operatorname{Im}-\mathrm{F}_{6}-\mathrm{Fe}$ & -1.266 & 526 & $9.80 \times 10^{5}$ & 5.99 & $92 \%$ & 2.05 & $2.71( \pm 0.30)$ \\
\hline FeTPP & -1.420 & 680 & $1.07 \times 10^{4}$ & 4.03 & $94-100 \%^{52}$ & 0.92 & $1.81( \pm 0.06)$ \\
\hline $\mathrm{FeTPPF}_{8}$ & -1.296 & 556 & $1.57 \times 10^{2}$ & 2.20 & - & 0.92 & $1.27( \pm 0.05)$ \\
\hline FeTPPF $_{20}$ & -1.106 & 366 & $1.88 \times 10^{1}$ & 1.27 & $96 \%^{53}$ & 0.92 & $1.16( \pm 0.05)$ \\
\hline
\end{tabular}

Table 1 Summary of electrochemical properties of the modified iron-porphyrin catalysts.

${ }^{a}$ Overpotential calculated as the difference between the $\mathrm{E}\left(\mathrm{Fe}^{\mathrm{l} / 0}\right)$ and $\mathrm{E}^{\circ}\left(\mathrm{CO}_{2} / \mathrm{CO}\right)=0.74 \mathrm{~V}$ vs NHE. ${ }^{\mathrm{b}} \mathrm{TOF}_{\max }$ estimated from Foot-of-the-Wave $(\mathrm{FOW})$ analysis. ${ }^{\mathrm{C}} \mathrm{Faraday}$ efficiency measured from bulk electrolysis experiments (see $\mathrm{SI}$ ). ${ }^{\mathrm{d}} \mathrm{CO}_{2}$ binding constant estimated using $\mathrm{CVs}_{\mathrm{s}}$ in dry $\mathrm{DMF}$ purged with $\mathrm{CO}_{2}$ measured at $1 \mathrm{~V} / \mathrm{s}$ (calculations in the $\mathrm{SI}$ ). ${ }^{\mathrm{e}}$ Kinetic Isotope Effect (KIE) calculated as average using different concentrations of $\mathrm{H}_{2} \mathrm{O} / \mathrm{D}_{2} \mathrm{O}$ (1.1 $\mathrm{M}$ to $5.5 \mathrm{M}$ ).

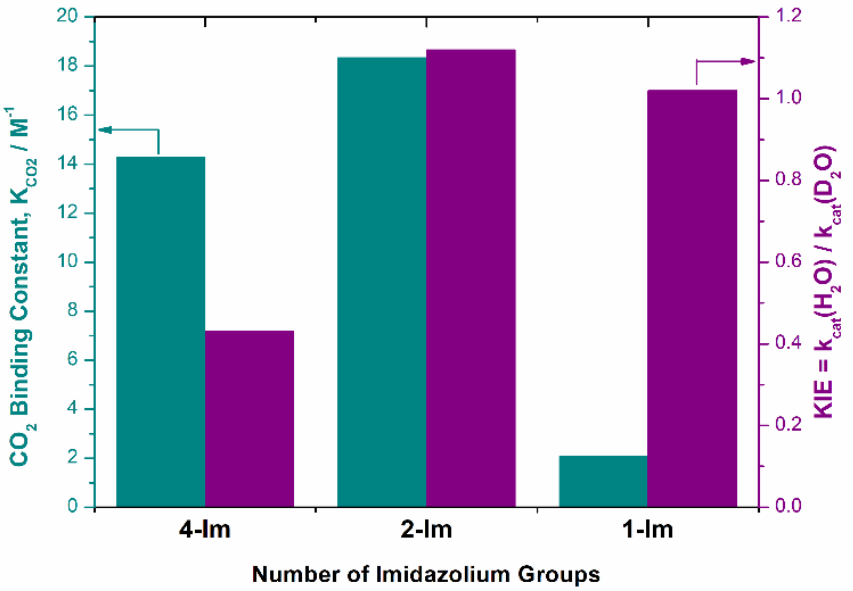

Figure 2 Comparison of the $\mathrm{CO}_{2}$ binding constant and Kinetic Isotope Effect (KIE) for the modified iron porphyrin complexes as a function of the number of imidazolium groups.

The protonation steps following $\mathrm{CO}_{2}$ binding are often reported to be the rate-limiting step in the electrocatalytic $\mathrm{CO}_{2}$ reduction by iron porphyrins. ${ }^{28,52}$ Kinetic isotope effect (KIE = $\left.k_{\text {cat, } \mathrm{H}_{2} \mathrm{O}} / k_{\text {cat, } \mathrm{D}_{2} \mathrm{O}}\right)$ was measured for each of the imidazolium derivatives using $\mathrm{H}_{2} \mathrm{O}$ or $\mathrm{D}_{2} \mathrm{O}$ as a proton or deuterium source. Both 2-Im-Fe and 1-Im-Fe showed a normal primary KIE of 1.12 and 1.02 , respectively, but interestingly, the 4-Im-Fe showed a strong inverse primary KIE of 0.43 (further evidence pointed by Figures S20-22). The latter effect possibly indicates that for the 4-Im-Fe derivative, a pre-equilibrium (initial substrate stabilization), preceding the rate-determining protonation step, has a significant contribution to the overall kinetics of the reaction. Compared to $\mathbf{2}-\mathbf{I m}-\mathbf{F e}$ and $\mathbf{1}-\mathbf{I m}-\mathbf{F e}$ derivatives, the $\mathbf{4 -}$ Im-Fe catalyst has a unique configuration where the four imidazolium pillars form a positively-charged channel above the metal center. This configuration can induce a $\mathrm{H}_{2} \mathrm{O} / \mathrm{D}_{2} \mathrm{O}$ molecular nanoconfinement which could possibly explain the peculiar behavior of the 4-Im-Fe catalyst. Recently, such $\mathrm{H}_{2} \mathrm{O}$ molecular nanoconfinement are being actively investigated in various ionic liquids including those based on imidazolium groups. $^{54-56}$

The nonconforming trend in $\mathrm{CO}_{2}$ binding constant and KIE with respect to the number of imidazolium groups in the second coordination sphere of the iron porphyrins indicates that behind the observed remarkable correlation between the overall driving force and the catalytic rate may also lie significant changes in the rate-determining step. Initial experimental data presented here dictates that there is a switch of rate-determining step when changing from 4-Im-Fe to 2-Im-Fe and to 1-Im-Fe. However, to probe such differences in-depth quantum chemical calculations and physicomathematical analysis of the reaction steps in the catalytic cycle with relevant experimental validation through intermediate characterization are necessary, which are beyond the scope of this study.

\section{Combining through-structure electronic effects and through-space electrostatic interactions}

As discussed above, both through-structure inductive effects and through-space electrostatic interactions can be employed to adjust the redox potential of the $\mathrm{Fe}^{1 / 0}$ redox couple and thus shift the catalytic potential of $\mathrm{CO}_{2}$ reduction along the established correlations. Additionally, the through-space electrostatic interactions fulfill an extra role of enhancing the reaction rate due to the through-space stabilization of the Fe$\mathrm{CO}_{2}{ }^{-}$intermediate. To investigate what catalytic modifications the association of these two different effects may lead to, we developed a new analogue catalyst $\mathbf{1}-\mathbf{I m}-\mathbf{F}_{\mathbf{6}}-\mathbf{F e}$ combining six fluorine groups as through-structure electron-withdrawing groups and one imidazolium arm to induce the through-space electrostatic interactions.

FOW analysis of the catalytic current observed with 1-Im- $\mathbf{F}_{6}-\mathbf{F e}$ catalyst under $\mathrm{CO}_{2}$ atmosphere confirms a dual action of the six fluorine groups and the methylimidazolium group (Figure 3). Indeed, $\mathbf{1}-\mathbf{I m}-\mathbf{F}_{6}-\mathbf{F e}$ displays a catalytic potential (90 mV) more positive than that of its nonfluorinated 1-Im-Fe analogue 
and thus 1-Im- $\mathbf{F}_{6}-\mathbf{F e}$ operates with a catalytic potential closer to that of FeTPP- $\mathbf{F}_{\mathbf{8}}\left(E_{\text {cat }}^{0}\left(\mathbf{1}-\mathbf{I m}-\mathbf{F}_{6}-\mathbf{F e}\right)=-1.266 \mathrm{~V}\right.$ and $\left.E_{\text {cat }}^{0}\left(\mathbf{F e T P P}-\mathbf{F}_{8}\right)=-1.296 \mathrm{~V}\right)$. However, thanks to the throughspace stabilization of the $\mathrm{Fe}-\mathrm{CO}_{2}{ }^{-}$intermediate by the methylimidazolium group, $\mathbf{1}-\mathbf{I m}-\mathbf{F}_{6}-\mathbf{F e}$ displays a much higher TOF value (Figure $3 c$ ). The $\mathbf{1}-\mathbf{I m}-\mathbf{F}_{6}-\mathbf{F e}$ catalytic performance falls in between the through-structure and through-space linear correlations, demonstrating that extra level of tunability of the catalytic activity of iron porphyrins can be achieved by combining through-structure inductive effects and throughspace electrostatic interactions.
KIE value of 2.71 compared to either 1-Im-Fe (1.02) or FeTPP$\mathbf{F}_{8}$ (1.27) indicating that the combination of electronwithdrawing fluorine groups and cationic methylimidazolium groups induces a more significant dependence of the overall rate of the reaction on the protonation step. The notable increase in the TOF of the $\mathbf{1}-\mathbf{I m}-\mathbf{F}_{\mathbf{6}}-\mathbf{F e}$, despite the dragging effects of fluorine groups on the reaction rate, but without reaching the newly-established through-space linear correlation with imidazolium groups points out that a different contribution to the reaction rate from the $\mathrm{CO}_{2}$ binding and the protonation steps is at play here and not just the result of
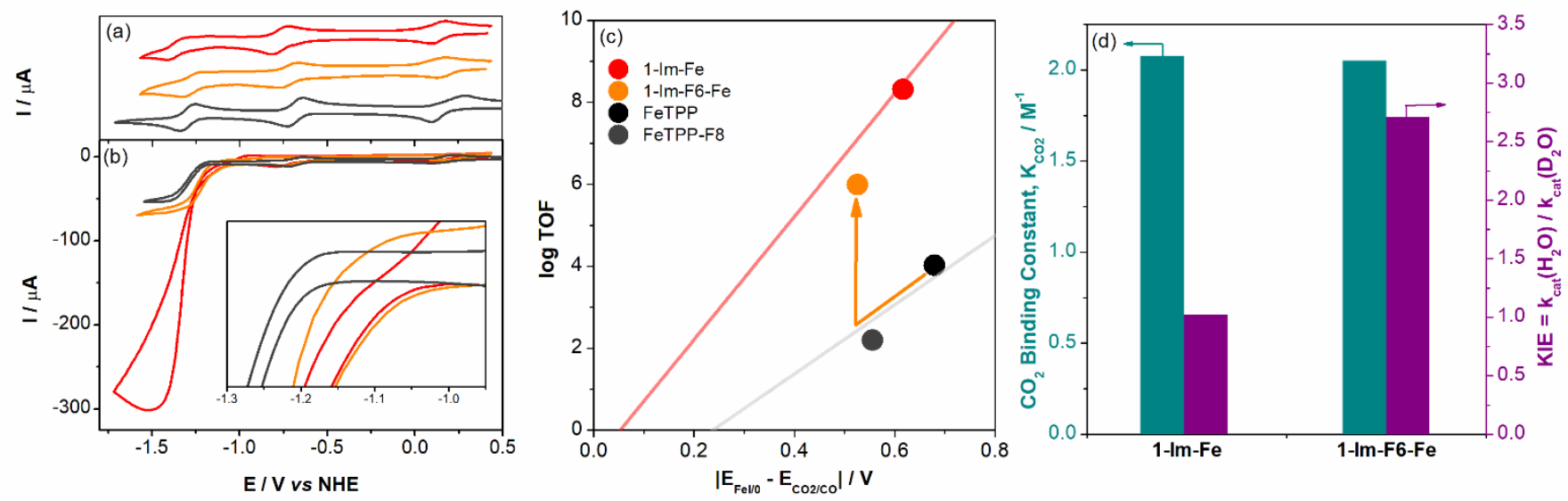

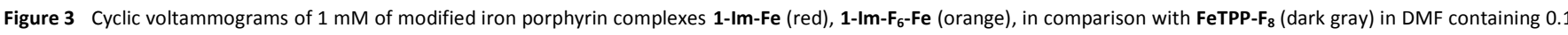
$\mathrm{M}\left[\mathrm{Bu}_{4} \mathrm{~N}\right] \mathrm{PF}_{6}$ at $25^{\circ} \mathrm{C}$ (a) under argon and (b) under $\mathrm{CO}_{2}$ with $5.5 \mathrm{M} \mathrm{H}_{2} \mathrm{O}$. (c) Comparison of the turnover frequency (TOF) calculated from FOW analysis as a function of catalytic overpotentials $\left(E_{\mathrm{CO}_{2} / \mathrm{CO}}^{0}=-0.74 \mathrm{~V}\right.$ vs NHE). Catalytic performance of nonfunctionalized FeTPP (black) and FeTPP- $\mathbf{F}_{\mathbf{8}}$ (dark gray) are included for comparison. (d) Comparison of the $\mathrm{CO}_{2}$ binding constant and KIE between 1-Im-Fe (red), 1-Im- $\mathrm{F}_{6}-\mathrm{Fe}$ (orange).

We previously reported that despite the difference in their $E\left(\mathrm{Fe}^{1 / 0}\right)$ values (see Table 1 ), complexes FeTPP, FeTPP- $\mathbf{F}_{\mathbf{8}}$ and FeTPP- $\mathbf{F}_{20}$ display similar $\mathrm{CO}_{2}$ binding constants $\left(K_{\mathrm{CO}_{2}}=0.92 \mathrm{M}^{-}\right.$ $\left.{ }^{1}\right)$ indicating that the nucleophilic strength of $\mathrm{Fe}^{\mathrm{O}}$ species in these three complexes have no significant effect on $\mathrm{CO}_{2}$ binding. As mentioned earlier, the presence of an imidazolium arm in 1-Im-Fe increases the $\mathrm{CO}_{2}$ binding constant $\left(\mathrm{K}_{\mathrm{CO}_{2}}=2.08\right.$ $\mathrm{M}^{-1}$ ) but here too, the introduction of six fluorine atoms as electron withdrawing groups (1-Im- $\left.\mathbf{F}_{\mathbf{6}}-\mathbf{F e}\right)$, although it shifts $E\left(\mathrm{Fe}^{1 / 0}\right)$ anodically by $90 \mathrm{mV}$, does not affect the $\mathrm{CO}_{2}$ binding constant $\left(\mathrm{K}_{\mathrm{CO}_{2}}=2.05 \mathrm{M}^{-1}\right)$ (Figure $3 \mathrm{~d}$ ). In addition, the fluorinated-derivative $\mathbf{1}-\mathbf{I m}-\mathbf{F}_{6}-\mathbf{F e}$ has a higher normal primary

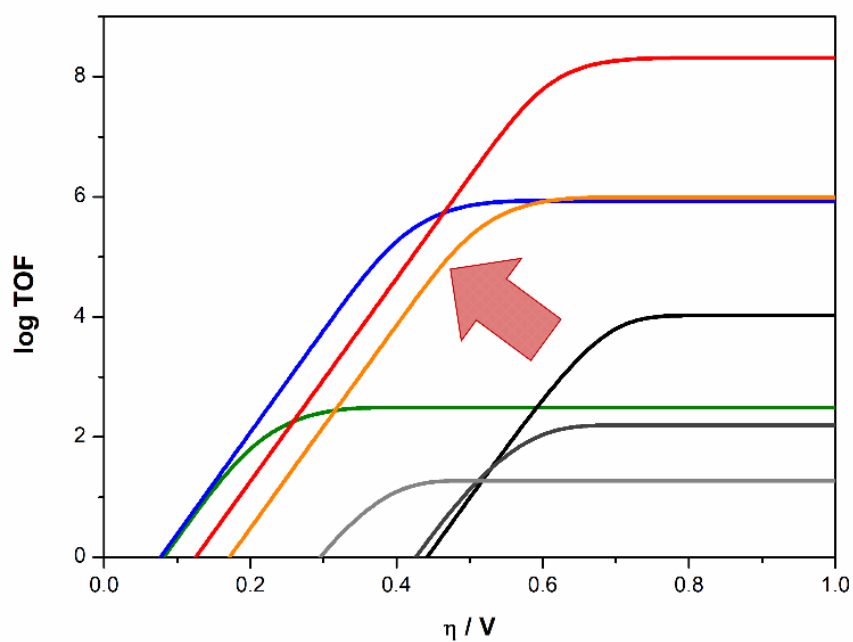

$T_{\text {Figure }} 4$ Catalytic Tafel plots of the imidazolium-decorated iron porphyrin catalysts (4Im-Fe in green, 2-Im-Fe in blue, 1-Im-Fe in red, 1-Im-F6-Fe in orange) showing the electrocatalytic improvements (enhancement of TOF and decrease of overpotential) in comparison with the classical through-structure strategy (FeTPP in black, FeTPP-F8 in dark gray, FeTPP-F2O in gray). Condition: $\mathrm{CO}_{2}$-saturated DMF with $5.5 \mathrm{M} \mathrm{H}_{2} \mathrm{O}$. summation of each of the independent effects. This will be further probed in additional experimental and theoretical investigations currently being performed in our group.

\section{Conclusions}

The through-structure electronic effects of donor and withdrawing groups have commonly been plugged in molecular based complexes to modulate the electronic and catalytic properties of metal complexes. In the field of $\mathrm{CO}_{2}$ reduction, the presence of electron-withdrawing groups led to a bargain between a consequent drop in the overpotential and the diminished electrocatalytic rate. With the mindset to improve the electrocatalytic properties of molecular catalysts, chemists have successfully implemented different functionalities such as hydrogen bonding groups, proton relays and electrostatic interactions in the second coordination sphere that have contributed to modulate both electrochemical parameters. As a state of the art, two iron porphyrin derivatives holding cationic tetra-methylammonium and imidazolium functions stand out in the targeted window for catalysts with low overpotential and high turnover frequencies. Such an approach was inspired from the electrostatic interactions that prevail in the functioning of enzymes. We have reported herein a series of substituted iron porphyrin systems holding different number of imidazolium 
units, the tetra-, di- and mono-substituted derivatives with the target to bring insights in the structure/reactivity pattern. We found that the drop in overpotential of these catalysts is a function of the number of embarked imidazolium units. Importantly, we evidenced a gain of six orders of magnitude for the turnover frequencies from the tetra- to the monosubstituted catalyst. Of particular interest, we observed that the trend in the electrocatalytic performance of through-space electrostatic interaction models outperforms the classic electronic effects strategy, as summarized by the catalytic Tafel plots in Figure 4. Furthermore, when both electrostatic and electronic features of one imidazolium unit and six fluorine atoms respectively are embarked in a model, here too we noticed a combined effect resulting in a three order magnitude gain in the TOF with a consequential fall in the overpotential. Further work is in progress in our labs to provide both theoretical insights and the best combination of chemical functions in the quest for cost-efficient catalytic systems for $\mathrm{CO}_{2}$ reduction.

\section{Conflicts of interest}

There are no conflicts to declare.

\section{Acknowledgements}

This work has been supported by the French National Research Agency (ANR-19-CE05-0020-02, LOCO). We thank CNRS, CEA Saclay, LABEX CHARMMMAT, ICMMO and University ParisSaclay for the financial support and Ecole Doctorale 2MIB for PhD fellowship (for A. Khadhraoui). We also thank the synthesis support facility (Pôle Synthèse) at ICMMO for their help with the synthesis of the starting porphyrin platform.

\section{Notes and references}

1 D. A. N. Ussiri and R. Lal, in Carbon Sequestration for Climate Change Mitigation and Adaptation, Springer, Cham, 2017, ch. Carbon Capture and Storage in Geologic Formations, pp. 497-545.

2 T. P. Senftle and E. A. Carter, Acc. Chem. Res., 2017, 50, 472475.

3 M. Aresta, A. Dibenedetto and A. Angelini, Chem. Rev., 2014, 114, 1709-1742.

4 Q. Liu, L. Wu, R. Jackstell and M. Beller, Nature Communications, 2015, 6, 5933.

5 S. C. Roy, O. K. Varghese, M. Paulose and C. A. Grimes, ACS Nano, 2010, 4, 1259-1278.

6 G. A. Olah, Angew. Chem. Int. Ed., 2005, 44, 2636-2639.

7 Q.-L. Zhou, Angew. Chem. Int. Ed., 2016, 55, 5352-5353.

8 O. S. Bushuyev, P. De Luna, C. T. Dinh, L. Tao, G. Saur, J. van de Lagemaat, S. O. Kelley and E. H. Sargent, Joule, 2018, 2, 825-832.

9 J. Schneider, H. Jia, J. T. Muckerman and E. Fujita, Chem. Soc. Rev., 2012, 41, 2036-2051.

10 R. Francke, B. Schille and M. Roemelt, Chem. Rev., 2018, 118, 4631-4701.

11 F. Wang, ChemSusChem, 2017, 10, 4393-4402.
12 H. Takeda, C. Cometto, O. Ishitani and M. Robert, ACS Catalysis, 2017, 7, 70-88

13 M. Cokoja, C. Bruckmeier, B. Rieger, W. A. Herrmann and F. E. Kühn, Angew. Chem. Int. Ed., 2011, 50, 8510-8537.

14 N. Elgrishi, M. B. Chambers, X. Wang and M. Fontecave, Chem. Soc. Rev., 2017, 46, 761-796.

15 K. E. Dalle, J. Warnan, J. J. Leung, B. Reuillard, I. S. Karmel and E. Reisner, Chem. Rev., 2019, 119, 2752-2875.

16 T. Katsuhiro, H. Kazuya, S. Hideo and T. Shinobu, Chem. Lett. 1979, 8, 305-308.

17 M. Hammouche, D. Lexa, M. Momenteau and J. M. Saveant, J. Am. Chem. Soc., 1991, 113, 8455-8466.

18 C. Costentin and J.-M. Savéant, Nature Reviews Chemistry, 2017, 1, 0087.

19 A. W. Nichols and C. W. Machan, Frontiers in Chemistry, $2019,7$. 20 F. Franco, S. Fernández and J. Lloret-Fillol, Current Opinion in Electrochemistry, 2019, 15, 109-117.

21 P. Gotico, Z. Halime and A. Aukauloo, Dalton Transactions, 2020, 49, 2381-2396.

22 Y. Matsubara, ACS Energy Letters, 2019, DOI: 10.1021/acsenergylett.9b01180, 1999-2004.

23 I. Bhugun, D. Lexa and J.-M. Savéant, The Journal of Physical Chemistry, 1996, 100, 19981-19985.

24 I. Azcarate, C. Costentin, M. Robert and J.-M. Savéant, J. Am. Chem. Soc., 2016, 138, 16639-16644.

25 I. Azcarate, C. Costentin, M. Robert and J.-M. Savéant, The Journal of Physical Chemistry C, 2016, 120, 28951-28960.

26 C. Costentin and J.-M. Savéant, Nature Reviews Chemistry, 2017, 1, 0087.

27 C. Costentin, S. Drouet, M. Robert and J.-M. Savéant, Science, 2012, 338, 90-94.

28 C. Costentin, G. Passard, M. Robert and J.-M. Savéant, J. Am. Chem. Soc., 2014, 136, 11821-11829.

29 A. Khadhraoui, P. Gotico, B. Boitrel, W. Leibl, Z. Halime and A. Aukauloo, Chem. Commun., 2018, 54, 11630-11633.

30 E. Nichols, J. S. Derrick, S. K. Nistanaki, P. T. Smith and C. J. Chang, Chemical Science, 2018, 9, 2952-2960.

31 P. Sen, B. Mondal, D. Saha, A. Rana and A. Dey, Dalton Transactions, 2019, DOI: 10.1039/C8DT03850C.

32 P. Gotico, B. Boitrel, R. Guillot, M. Sircoglou, A. Quaranta, Z. Halime, W. Leibl and A. Aukauloo, Angew. Chem. Int. Ed., 2019, 58, 4504-4509.

33 S. Sung, X. Li, L. M. Wolf, J. R. Meeder, N. S. Bhuvanesh, K. A. Grice, J. A. Panetier and M. Nippe, J. Am. Chem. Soc., 2019, 141, 6569-6582.

34 A. Warshel, Acc. Chem. Res., 1981, 14, 284-290.

35 P. K. Sharma, Z. T. Chu, M. H. M. Olsson and A. Warshel, Proceedings of the National Academy of Sciences, 2007, 104, 96619666.

36 A. Warshel, Proceedings of the National Academy of Sciences, 1978, 75, 5250-5254.

37 C.-H. Lee and J. S. Lindsey, Tetrahedron, 1994, 50, 11427-11440. 38 J. S. Lindsey, I. C. Schreiman, H. C. Hsu, P. C. Kearney and A. M. Marguerettaz, The Journal of Organic Chemistry, 1987, 52, 827-836. 39 J. P. Collman, R. R. Gagne, C. Reed, T. R. Halbert, G. Lang and W. T. Robinson, J. Am. Chem. Soc., 1975, 97, 1427-1439.

40 A. Didier, L. Michaudet, D. Ricard, V. Baveux-Chambenoît, P. Richard and B. Boitrel, Eur. J. Org. Chem., 2001, 2001, 1927-1926. 41 Z. Halime, M. Lachkar, T. Roisnel, E. Furet, J. F. Halet and B. Boitrel, Angew. Chem. Int. Ed. Engl., 2007, 46, 5120-5124.

42 I. Hijazi, T. Roisnel, P. Even-Hernandez, E. Furet, J.-F. Halet, O. Cador and B. Boitrel, J. Am. Chem. Soc., 2010, 132, 10652-10653. 
43 C. Römelt, J. Song, M. Tarrago, J. A. Rees, M. van Gastel, T. Weyhermüller, S. DeBeer, E. Bill, F. Neese and S. Ye, Inorg. Chem., 2017, 56, 4745-4750.

44 C. Römelt, S. Ye, E. Bill, T. Weyhermüller, M. van Gastel and F. Neese, Inorg. Chem., 2018, 57, 2141-2148.

45 C. Costentin, M. Robert and J.-M. Savéant, Acc. Chem. Res., 2015, 48, 2996-3006.

46 V. Artero and J.-M. Saveant, Energy \& Environmental Science, 2014, 7, 3808-3814.

47 C. Costentin and J.-M. Savéant, J. Am. Chem. Soc., 2017, 139, 8245-8250.

48 M. L. Pegis, B. A. McKeown, N. Kumar, K. Lang, D. J. Wasylenko, X. P. Zhang, S. Raugei and J. M. Mayer, ACS Central Science, 2016, 2, 850-856.

49 M. L. Pegis, C. F. Wise, B. Koronkiewicz and J. M. Mayer, J. Am. Chem. Soc., 2017, 139, 11000-11003.

50 M. L. Pegis, C. F. Wise, D. J. Martin and J. M. Mayer, Chem. Rev., 2018, 118, 2340-2391.

51 C. Costentin and J.-M. Savéant, J. Am. Chem. Soc., 2018, 140, 16669-16675.

52 C. Costentin, S. Drouet, G. Passard, M. Robert and J.-M. Savéant, J. Am. Chem. Soc., 2013, 135, 9023-9031.

53 B. Zhao, H. Lei, N. Wang, G. Xu, W. Zhang and R. Cao, Chemistry - A European Journal, 2020, 26, 4007-4012.

54 K. Saihara, Y. Yoshimura, S. Ohta and A. Shimizu, Scientific Reports, 2015, 5, 10619.

55 A. Verma, J. P. Stoppelman and J. G. McDaniel, International Journal of Molecular Sciences, 2020, 21, 403.

56 C. Ma, A. Laaksonen, C. Liu, X. Lu and X. Ji, Chem. Soc. Rev., 2018, 47, 8685-8720. 